\title{
Dinâmica da mudança do uso e cobertura da terra em uma paisagem da Caatinga protegida e sua zona de amortecimento
}

(1) Os estudos voltados a dinâmica dos usos e coberturas da terra no domínio Caatinga ainda são insuficientes, principalmente quando voltados ao entendimento de como esse fenômeno ocorre dentro das paisagens protegidas e seus entornos. Portanto, com base nesta premissa a seguinte pesquisa objetivou diagnosticar mudanças dos usos e cobertura da terra em uma paisagem de Caatinga protegida e sua zona de amortecimento levando em conta o período pré e pós-criação da UC; (2) Logo, lançou-se uso do método híbrido de classificação, a fim de se obter as classes de cobertura da terra ao longo do espaço e tempo da paisagem do Parque Estadual Mata da Pimenteira, Pernambuco, Nordeste do Brasil; (3) Os resultados permitiram perceber aumento das principais classes indicativas de vegetação arbustiva e arbóreo-arbustiva, crescendo em aproximadamente 1.718,1 ha para a zona de amortecimento e 225.3 ha na área protegida; (4) A partir deste trabalho pode ser constatado que a criação da UC auxiliou no restabelecimento da composição da paisagem, promovendo a recuperação de áreas degradadas. Além disso, permitiu perceber que apesar do aumento da vegetação sobre a paisagem ocorreu uma intensificação do uso das áreas do entorno, com o aumento de áreas com solo Exposto.

Palavras-chave: Áreas protegidas; Uso e cobertura da terra; Caatinga.

\section{Land use and land cover change dynamics in a protected Caatinga's landscape and its buffer zone}

\begin{abstract}
(1) Studies on land use and land cover in the Caatinga domain are still insufficient, especially when they are aimed at understanding how this phenomenon occurs within protected landscapes and their surroundings. Therefore, based on this premise below, the research aims to diagnose changes in land use and land cover in a protected Caatinga landscape and its buffer zone, taking into account the pre and post-production period of the UC; (2) Soon, the use of the hybrid classification method was launched, in order to obtain land cover classes over the space and time of the landscape of the Mata da Pimenteira State Park, Pernambuco, Northeast Brazil; (3) The results made it possible to perceive the increase in the main indicative classes of shrub and tree-shrub vegetation, growing approximately 1,718.1 ha for a buffer zone and 225.3 ha in the protected area; (4) From this work, it can be seen that the creation of UC helped to reestablish the landscape composition, promoting the recovery of degraded areas. In addition, it was possible to notice that, despite the increase in vegetation over the landscape, there was an intensification of the use of areas of interest, with an increase in areas with exposed soil.
\end{abstract}

Keywords: Protected areas; Land use land cover; Caatinga.

Topic: Conservação da Biodiversidade

Reviewed anonymously in the process of blind peer
Received: 01/12/2020

Approved: $23 / 12 / 2020$
Joécio Santos Sousa

Universidade Federal Rural de Pernambuco, Brasil

http://lattes.cnpq.br/1617178819319314

jdonnellys2015@gmail.com

Ednilza Maranhão dos Santos

Universidade Federal Rural de Pernambuco, Brasil

http://lattes.cnpq.br/5812920432455297

ednilzamaranhao@gmail.com
Referencing this:

SOUSA, J. S.; SANTOS, E. M.. Dinâmica da mudança do uso e cobertura da terra em uma paisagem da Caatinga protegida e sua zona de amortecimento. Revista Ibero Americana de Ciências Ambientais, v.11, n.7, p.219-234, 2020. DOI: http://doi.org/10.6008/CBPC21796858.2020 .007 .0020 


\section{INTRODUÇÃO}

As áreas protegidas são espaços criados e definidos legalmente com o intuito de garantir a proteção de um acervo genético (JUSYS, 2016), biótico, abiótico e social dos biomas com características naturais relevantes e que sejam estrategicamente indispensáveis à promoção do desenvolvimento sustentável de uma região, buscando minimizar as interferências antrópicas em seus limites (SCHULZE et al., 2018). Estimase que cerca de $15 \%$ da porção territorial do planeta e $6.96 \%$ dos oceanos são cobertos por áreas protegidas (HUMMEL et al., 2018). No Brasil, $29.42 \%$ de toda a sua área continental e $26.62 \%$ de seus oceanos estão protegidos por Unidades de Conservação (UC), que constituem um espaço institucionalizado e protegido por leis mais consolidadas.

As áreas protegidas estão sob constantes ameaças, principalmente ao tratá-las como as formas mais comuns de proteção da biodiversidade, dos ecossistemas e paisagens (BAILEY et al., 2016). As UC's têm importância de garantir a manutenção da biodiversidade e todos os seus serviços e a sobrevivência humana, bem como, a proteção de ecossistemas (FIGUEIRÊDO et al., 2013). Onde se busca interligar a dualidade do desenvolvimento econômico com a conservação dos recursos naturais.

As ameaças a estas áreas em sua grande maioria são decorrentes de atividade antrópicas, em consequência da exploração direta dos recursos, ou por constantes modificações nas regiões circundantes, podendo provocar a degradação ou prejuízos ao equilíbrio natural e a biodiversidade alvo (SCHULZE et al., 2018).

Sabe-se que a cobertura da terra se refere às fisionomias características do espaço físico, tais como, rios, lagos, vegetação, relevo, etc. Enquanto que os usos dizem respeito a maneira como a terra tem sido utilizada pelo ser humano (RAWAT et al., 2015). As coberturas da terra são influenciadas diretamente pelas práticas de uso e vice-versa, as quais por sua vez sofrem influências das pressões políticas vigentes, demográficas, econômicas, entre outras (RAWAT et al., 2015).

Diante disso, a mudança do uso da terra no entorno de áreas protegidas tem diminuído sua capacidade de conservação e manutenção de processos ecológicos (LIMA et al., 2018), seja pela perda ou isolamento de habitats (YE et al., 2007). Principalmente ao se perceber que as interações entre os usos humanos dados ao espaço físico e as práticas de preservação dos ecossistemas tornaram-se mais complexas (DEFRIES et al., 2007), em especial devido à necessidade de inserção das comunidades do entorno no processo de gestão.

As zonas de amortecimento cumprem importantes papéis multifuncionais (JUSYS, 2016). Elas são elementos limitantes dos impactos das ações humanas sobre a natureza protegida, funcionando como um "absorvedor de choques" (AHMED et al., 2017). Usualmente essas áreas são estabelecidas para definir usos sustentáveis dos recursos, bem como, ser uma fonte de renda para a população local (WATSON et al., 2014), agindo como um espaço de transição entre uma região com alta intensidade para baixa intensidade de proteção (AHMED et al., 2017).

No Brasil, estas áreas são entendidas como: "o entorno de uma unidade de conservação, onde as 
atividades humanas estão sujeitas a normas e restrições específicas, com o propósito de minimizar os impactos negativos sobre a unidade" (BRASIL, 2000). Entretanto, percebe-se que as mudanças do uso e cobertura da terra ocorrem dentro destas zonas, principalmente provocados por interações entre os sistemas naturais e socioeconômicos (JIA et al., 2004).

Sendo assim, o delineamento da zona de amortecimento é realizado levando em consideração critérios multivariados ligados às questões dos usos tradicionais da terra, práticas agrícolas e agropecuárias, influenciados por características físicas da paisagem (fatores abióticos), ecológicos, legais e políticos (AHMED et al., 2017).

A intensificação dos usos de áreas protegidas e zonas de amortecimento dependem quase que exclusivamente de quais recursos essas áreas dispõem, assim como também, de quais forças geram pressão para que estes recursos sejam utilizados. Por exemplo, as florestas tropicais sazonalmente secas brasileiras, as quais formam o domínio Caatinga, correspondem à região semiárida mais populosa e biodiversa do mundo (BRASIL, 2019), possuindo aproximadamente mais de 20 milhões de habitantes (FRANÇA-ROCHA et al., 2007). Além disso, a região agrega a população mais pobre e que depende diretamente dos recursos disponíveis na natureza (AHMED et al., 2017).

Segundo o último relatório sobre a situação do domínio Caatinga quanto a sua cobertura vegetal, diagnosticou que apenas pouco mais da metade, 53.38\% da vegetação original permanece remanescente (JIA et al., 2004). Somado a esse contexto, os estudos relacionados aos usos insustentáveis e mudanças da cobertura da terra na Caatinga, são os menos conhecidos quando comparados aos demais domínios brasileiros (BEUCHLE et al., 2015).

O sensoriamento remoto atualmente traduz-se como uma das ferramentas mais utilizadas e eficientes para o monitoramento ambiental da dinâmica da vegetação, desde pequenos fragmentos à grandes extensões de áreas florestadas, para análises de usos e coberturas da terra, acompanhamento das mudanças climáticas, entre outros propósitos (HUTT et al., 2016). Somado a isso, o uso dos Sistemas de Informação Geográfica (GIS) ligado ao efetivo monitoramento e análise dos padrões de mudança do uso e cobertura da terra são indispensáveis para se atingir efeitos positivos na gestão dos recursos naturais e promoção da sustentabilidade (BADJANA et al., 2015).

Portanto, a presente pesquisa busca responder a seguinte pergunta: (a) como ocorreram as mudanças do uso e cobertura da terra na paisagem de onde hoje se localiza a zona de amortecimento do Parque Estadual Mata da Pimenteira ao longo de 10 anos. Sendo assim, este trabalho objetivou diagnosticar a variação da mudança do uso e cobertura da terra do Parque Estadual Mata da Pimenteira (uma floresta tropical sazonalmente seca) e sua zona de amortecimento. E especificamente, (i) analisar as mudanças espaço-temporais do uso e cobertura da terra entre os anos de 2008 e 2018. (ii) comparar as mudanças do uso e cobertura da terra entre os períodos pré e pós-criação do Parque Estadual Mata da Pimenteira. 


\section{METODOLOGIA}

\section{Área de estudo}

O Parque Estadual Mata da Pimenteira (Lat: 07ㅇ 56' 02" S; Long: 038 18’05") é uma Unidade de Conservação do grupo de Proteção Integral (BRASIL, 2000) localizada no município de Serra Talhada no Estado de Pernambuco (Brasil). Criado por meio do Decreto Estadual no 37.823, de 2012, o parque recebe a alcunha de primeira UC estadual localizada dentro do domínio da Caatinga (floresta tropical sazonalmente seca), especificamente do tipo arbórea arbustiva (SANTOS et al., 2013) e ocupa segundo seu plano de manejo uma área de 887.24 ha, enquanto que sua zona de amortecimento ocupa um total de $6.882,92$ ha de extensão.

O Parque Estadual Mata da Pimenteira está inserido na unidade geoambiental da Depressão Sertaneja que representa a paisagem típica do semiárido nordestino (SANTOS et al., 2013). É caracterizado por uma vegetação típica a Caatinga hiperxerófila, de fisonomía arbustivo-arbórea a arbórea e composição florística característica da Floresta Estacional Caducifólia Espinhosa (FERRAZ et al., 1998).

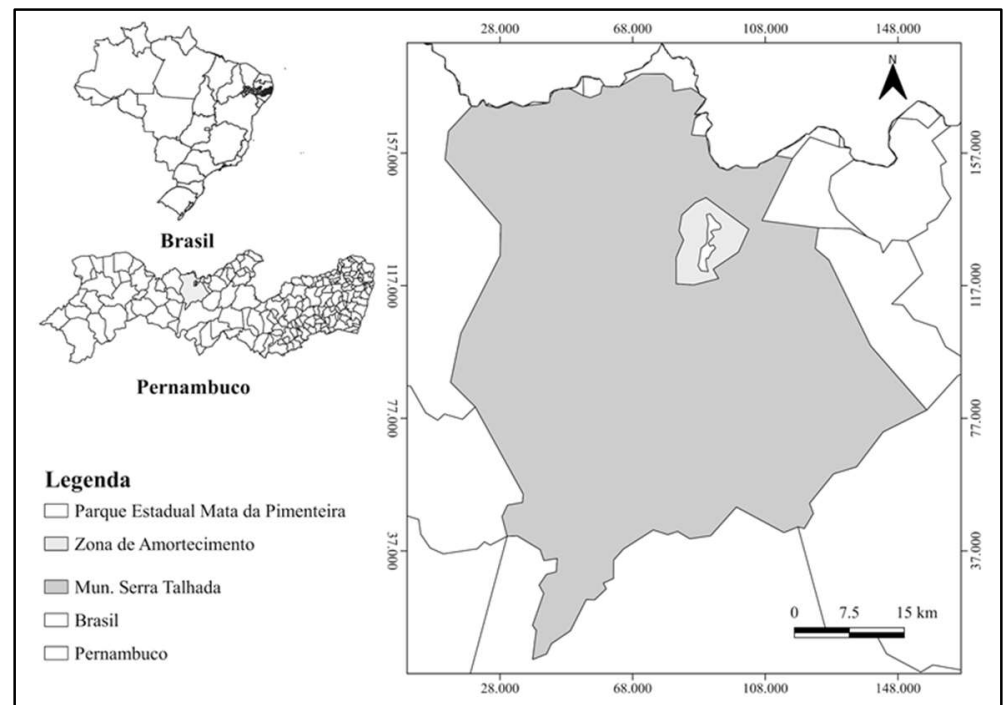

Figura 1: Localização do Parque Estadual Mata da Pimenteira e sua zona de amortecimento no município de Serra Talhada - PE.

\section{Aquisição e correção das imagens}

A fim de realizar as análises do uso e cobertura da terra da área de estudo, foi realizada a aquisição das imagens multiespectrais gratuitamente por meio do sítio eletrônico Earth Explorer ${ }^{1}$, do Serviço Geológico dos Estados Unidos (USGS), para os sensores Thematic Mapper (TM) - Landsat 5, Enhanced Thematic Mapper Plus (ETM+) - Landsat 7 e do Operational Land Imager (OLI) - Landsat 8 com resolução espacial de 30 metros (Tabela 1). Foram estabelecidos períodos de análise entre 2008 a 2018, com intervalo de dois anos entre o período estudado, abrangendo datas pré e pós-criação do Parque Estadual Mata da Pimenteira (Tabela 1). As escolhas destas imagens se deram baseadas em três fatores, primeiro optou-se pelo período classificado como seco para a região, pois por fazer parte do domínio Caatinga a área durante a seca perde as folhagens

\footnotetext{
${ }^{1}$ http://earthexplorer.usgs.gov
} 
(vegetação caducifólia) importante para a diferenciação entre paisagens vegetadas e expostas. Em seguida, optou-se por imagens com menor interferência de contaminação por nuvens e sombras de nuvens, e por fim, datas semelhantes nos respectivos anos estudados.

Tabela 1: Informações das imagens multiespectrais utilizadas nas análises.

\begin{tabular}{|l|l|l|l|}
\hline Sensor & Data & Path/row & Situação \\
\hline TM & 01 de novembro de 2008 & $216 / 65$ & Pré-criação da UC \\
\hline \multirow{3}{*}{ ETM+ } & 14 de outubro de 2010 & $216 / 65$ & \\
\cline { 2 - 3 } & 03 de outubro de 2012* & $216 / 65$ & \multirow{2}{*}{ Pós-criação da UC } \\
\cline { 2 - 3 } & 01 de outubro de 2014 & $216 / 65$ & \\
\cline { 2 - 3 } & 06 de outubro de 2016 & $216 / 65$ & \\
\cline { 2 - 3 } & 26 de setembro de 2018 & $216 / 65$ & \\
\hline
\end{tabular}

Por conseguinte, as imagens passaram por um processo de correção automática, transformando número digital (DN) para reflectância no topo da atmosfera (TOA) através do Semi-Automatic Classification Plugin - SCP no software gratuito QGIS (versão 2.12.3 - Lyon). Primeiramente foi extraído das bandas 1, 2, 3, 4, 5 e 7 o recorte referente à paisagem da zona de amortecimento da Mata da Pimenteira por meio da camada de máscara para sua posterior correção. Além disso, a imagens referentes ao satélite do sensor ETM+ foram corrigidas quanto aos erros das linhas de escala através da extensão Landsat 7 toolbox no SIG ArcGis 10.5 .

\section{Classificações do uso e cobertura da terra}

Após as correções das imagens quanto a reflectância procedeu-se com a mesclagem das bandas para gerar as combinações RGB (Figura 2.a), e então classificá-las através do método não-supervisionado, o qual por sua vez consiste na descrição e agrupamento de objetos com características próximas (USMAN et al., 2013). Os resultados obtidos (Figura 2.b) foram reclassificados e convertidos para polígonos para eventuais correções de classificação, bem como para calcular as áreas correspondentes a cada classe. Ao todo foram estabelecidas sete classes: Água, Vegetação Mais Densa, Vegetação Menos Densa, Área de Uso Antrópico, Solo Exposto, Rocha, Nuvens. As macro-classes correspondem aos termos genéricos para cada cobertura da terra identificada, que por sua vez agregam o maior número de fisionomias da paisagem estabelecidas para cada grupo 'clusterizado'.

Tabela 2: Uso e cobertura da terra da área de estudo e suas descrições.

\begin{tabular}{|l|l|}
\hline $\begin{array}{l}\text { Classes de uso e } \\
\text { cobertura da terra }\end{array}$ & Descrição \\
\hline Água & Áreas cobertas por corpos hídricos tais como: açudes, rios e riachos. \\
\hline Vegetação Mais Densa & Áreas compostas por vegetação arbóreo-arbustiva, arbóreas e com baixo estresse hídrico. \\
\hline Vegetação Menos Densa & Áreas com presença de vegetação arbustiva, herbáceas e gramíneas. \\
\hline Área de Uso Antrópico & $\begin{array}{l}\text { Espaços com a presença de atividades antrópicas ao longo da zona de amortecimento, tais como: } \\
\text { agropecuária, agricultura, assentamentos humanos, entre outros. }\end{array}$ \\
\hline Solo Exposto & Áreas compostas por manchas de solo desvegetadas. \\
\hline Rocha & Áreas com a presença de rochas. \\
\hline Nuvem & Contaminação por nuvens ou sombra de nuvens \\
\hline
\end{tabular}



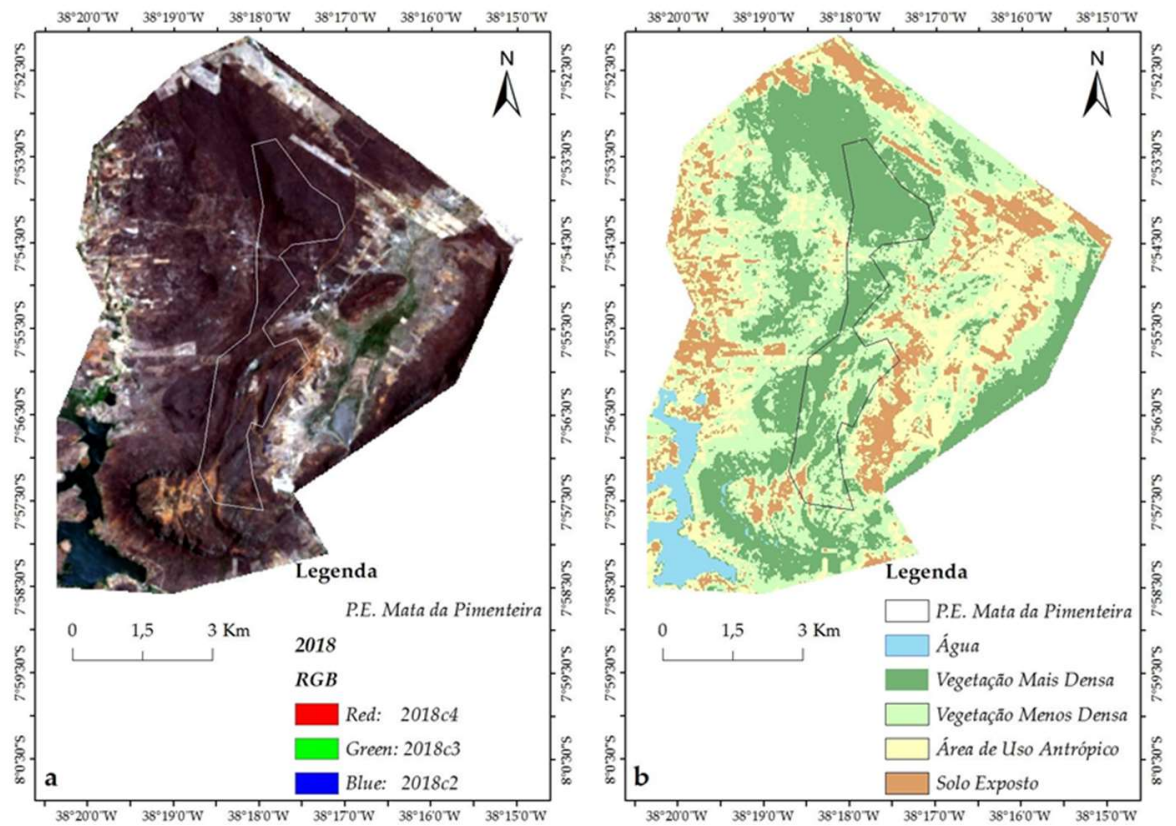

Figura 2: (a) Combinação RGB (4-3-2) das bandas do satélite Landsat 8 (OLI) referente ao ano de 2018 (Tabela. 1); (b) Resultado da classificação não-supervisionada da imagem RGB agrupada em 5 'clusters'.

\section{Avaliação da precisão de classificação}

A fim de conferir se as classes identificadas de uso e cobertura da terra observadas nas imagens classificadas correspondem à realidade, utilizou-se uma imagem de alta resolução do Google Earth Pro para a avaliação de precisão de classificação referente aos períodos estudados. Ao todo foram selecionados 760 pontos que correspondessem a cada classe de uso e cobertura estabelecida. Ao final, a partir da matriz de confusão obteve-se a precisão geral (Overall Accuracy) e o índice Kappa (COHEN, 1960).

\section{Detecção da mudança do uso e cobertura da terra}

Após a confirmação da precisão de classificação foi realizada a detecção da mudança da cobertura da terra ao longo dos anos estabelecidos. Este procedimento deu-se em pares de anos, ou seja, foi feita entre os anos de 1988 para 1998, 1998 para 2008, 2008 para 2018 e por fim, entre 1988 para 2018 através do plugin MOLUSCE no QGIS. A mudança entre as classes de cobertura da terra baseou-se no tamanho da área (em ha) de um período para o outro.

\section{Taxa de mudança anual}

As taxas de mudanças anuais para cada classe de uso e cobertura da terra foram calculadas levando em consideração a fórmula proposta por (BEUCHLE et al., 2015).

$$
r=(1 / t 2-t 1) x \ln (A 2 / A 1)
$$

Onde r é a taxa de mudança para cada classe de uso e cobertura da terra, A2 e A1 correspondem à classe de uso e cobertura no período final e inicial respectivamente, do ano avaliado, t2 e t1 são os anos final e inicial analisados para cada classe, respectivamente. 


\section{RESULTADOS}

\section{Classificação do uso e cobertura da terra e taxa de mudança anual}

\section{Zona de amortecimento}

Como pode ser constatado na Tabela 3 a dinamicidade hidrológica da região, principalmente por estar localizada em um cenário do sertão pernambucano, as fontes de água, em especial os açudes perderam massas de água ao longo dos anos notadamente atingindo seu ponto mais baixo no ano de 2016 perdendo 3.7\% de área ao se comprar com o ano anterior.

Para, além disso, a as classes correspondentes a composição vegetal da zona de amortecimento, a saber, 'vegetação mais densa' e 'vegetação menos densa', juntas são responsáveis por mais da metade da composição da paisagem, comportamento observado ao longo dos 10 anos. Nota-se que no ano inicial a classe 'vegetação menos densa' ocupa 38.2\% do total da área (Figura 3) o que corresponde a 2628.72 ha, contudo a mesma classe apresentou comportamento descendente ao longo da década tendo uma perda de 7.7\% de área no período. Já quanto à classe 'vegetação mais densa' evidenciou um aumento de 778.98 ha (Tabela 3), ou seja, um crescimento de $11.3 \%$ para o mesmo período.

Por conseguinte, a classe 'área de uso antrópico' corresponde à terceira classe com maior representatividade na paisagem da zona de amortecimento. Assim como constatado na Tabela 3 e na Figura 3 está chegou a compor mais de $27 \%$ do total da área no ano de 2014 , equivalente a 1899.63 hectares, e mesmo apesar da queda de -2.5\% entre os anos de 2014 e 2016, a mesma classe ao longo da década analisada apresentou um aumento de $2.6 \%$. Por fim, a classe 'solo exposto' manifestou uma perda de $-0.3 \%$ de sua área entre os anos de 2008 e 2018.

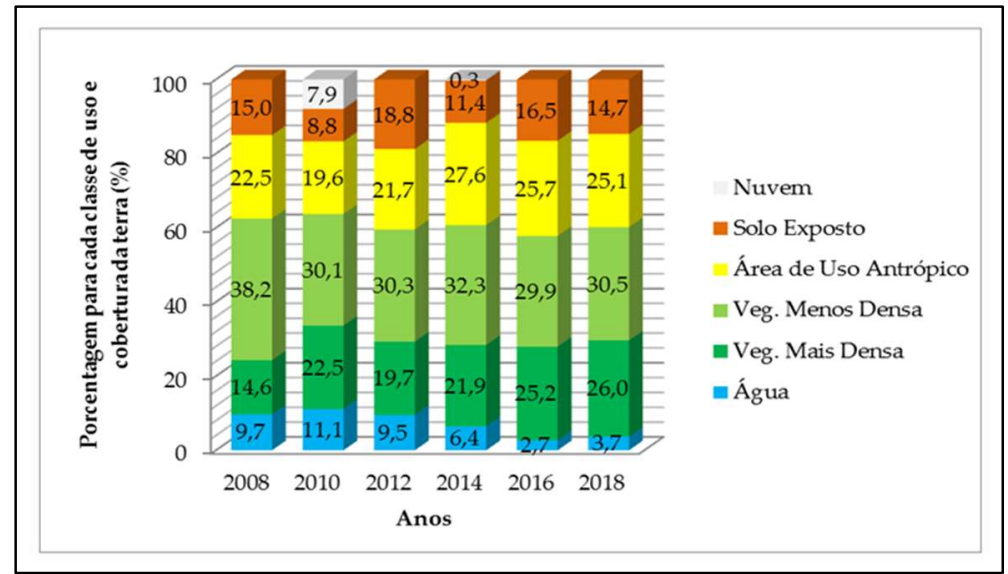

Figura 3: Porcentagem das classes de uso e cobertura da terra da zona de amortecimento da Mata da Pimenteira ao longo dos períodos pré-criação (2008 - 2010) e pós-criação (2012 - 2014 - 2016 - 2018) da unidade de conservação.

Já em relação às taxas de mudanças anuais, Tabela 4, verifica-se a classe correspondente à "vegetação mais densa" apresentou seguidas taxas positivas de mudanças entre os anos de 2012 a 2014 (0.05\%), 2014 e 2016 (0.07\%) e, por fim, entre 2016 e 2018 (0.01\%). Apenas entre o período de 2010 e 2012 evidenciou um decréscimo de $-0.06 \%$. E ao se observar a década analisada verifica-se que a referida classe apresentou um crescimento de $0.06 \%$, diferentemente a mesma situação não se repete para a classe "vegetação menos densa", pois a mesma mostrou uma queda de $-0.02 \%$ ao longo da década. 
Tabela 3: Área total e porcentagem das classes identificadas para a paisagem da zona de amortecimento do Parque Estadual Mata da Pimenteira no período Pré e Pós-criação da UC.

\begin{tabular}{|l|l|l|l|l|l|l|}
\hline \multirow{2}{*}{ Zona de Amortecimento } & Pré-criação & Pós-criação & \multicolumn{2}{l|}{} \\
\cline { 2 - 7 } & $\mathbf{2 0 0 8} / \mathbf{h a}$ & $\mathbf{2 0 1 0 / \mathbf { h a }}$ & $\mathbf{2 0 1 2} / \mathbf{h a}$ & $\mathbf{2 0 1 4} / \mathbf{h a}$ & $\mathbf{2 0 1 6 / \mathbf { h a }}$ & $\mathbf{2 0 1 8} / \mathbf{h a}$ \\
\hline Água & 664.59 & 765.06 & 656.16 & 443.87 & 187.04 & 251.95 \\
\hline Veg. Mais Densa & 1007.45 & 1547.13 & 1358.69 & 1508.79 & 1735.29 & 1786.43 \\
\hline Veg. Menos Densa & 2628.72 & 2072.8 & 2084.13 & 2225.96 & 2055.45 & 2101.49 \\
\hline Área de Uso Antrópico & 1549.25 & 1347.67 & 1491.754 & 1899.63 & 1766.47 & 1728.66 \\
\hline Solo Exposto & 1032.91 & 603.92 & 1292.4 & 785.94 & 1138.67 & 1014.39 \\
\hline Nuvens & 0 & 546.34 & 0 & 18.73 & 0 & 0 \\
\hline
\end{tabular}

Quanto à classe área de uso antrópico pode ser observado um crescimento nas taxas de mudanças anuais de 2010 a 2014, manifestando uma mudança positiva de $0.07 \%$. Por conseguinte, as taxas de mudanças permanecem negativas entre os anos de 2014 e 2016 e novamente entre 2016 e 2018 . Por fim, ao se observar isoladamente as classes de uso e cobertura da terra ao longo da década analisada, a classe 'água' foi a que apresentou a maior taxa de mudança negativa entre as classes observadas, apresentando uma taxa de $-0.10 \%$, seguida pela mudança positiva da classe 'vegetação mais densa' e, por sua vez, a classe 'solo exposto' não apresentou mudança durante a década.

Tabela 4: Taxa de mudanças anuais das classes de uso e cobertura da terra para a zona de amortecimento do Parque Estadual da Mata da Pimenteira no período Pré e Pós-criação da UC.

\begin{tabular}{|c|c|c|c|c|c|c|}
\hline \multirow{2}{*}{ Zona de Amortecimento } & \multicolumn{2}{|c|}{ Pré-criação } & \multicolumn{4}{|c|}{ Pós-criação } \\
\hline & $2008-2010$ & $2010-2012$ & $2012-2014$ & $2014-2016$ & $2016-2018$ & $2008-2018$ \\
\hline Água & 0,07 & $-0,08$ & $-0,20$ & $-0,43$ & 0,15 & $-0,10$ \\
\hline Veg. Mais Densa & 0,21 & $-0,06$ & 0,05 & 0,07 & 0,01 & 0,06 \\
\hline Veg. Menos Densa & $-0,12$ & 0,00 & 0,03 & $-0,04$ & 0,01 & $-0,02$ \\
\hline Área de Uso Antrópico & $-0,07$ & 0,05 & 0,12 & $-0,04$ & $-0,01$ & 0,01 \\
\hline Solo Exposto & $-0,27$ & 0,38 & $-0,25$ & 0,19 & $-0,06$ & 0,00 \\
\hline
\end{tabular}

\section{Parque Estadual Mata da Pimenteira}

Conforme observado na Figura 5 e na Tabela 6 verificam-se as variações das classes de uso e cobertura da terra para a área do Parque Estadual Mata da Pimenteira ao longo dos períodos pré e pós criação do mesmo. Nota-se que a classes vegetação mais densa e vegetação menos densa são as principais classes de uso e cobertura para a área da paisagem. É perceptível que elas compõem aproximadamente, e em muitas vezes, mais de $90 \%$ do total da paisagem. Isso se justifica devido ao fato de que a referida área sempre manteve uma composição vegetal conservada, apesar da existência dos projetos de agropecuários executados na área a partir de 1980.

Ao se comparar os dois períodos, observa-se que a classe área de uso antrópico diminui gradativamente ao longo dos anos pós-criação, partindo de 49.05 hectares no ano de 2012, o que correspondia a 5.2\% do total da área, para chegar no ano de 2018 correspondendo apenas $3.7 \%$ da paisagem do parque. Vale ressaltar que as áreas uso antrópico, apesar da proibição do uso direto dos recursos e do território da UC, conforme estabelece o SNUC, são representadas aqui pelas estradas oficiais que permeiam a região, assim como também as demais estradas vicinais que se distribuem ao longo do espaço.

Já as áreas correspondentes à classe 'solo exposto' durante os anos estudados comportou-se de forma oscilante, apresentando momentos de aumento de área com solos expostos, mas chegando ao ano de 2018 a apenas 16.9\%. Apesar disso, durante o período pós-criação da unidade de conservação essa classe 
atingiu seus momentos mais expressivos, tais como, 2012 e 2016, com $23.68 \%$ e $20.08 \%$ respectivamente.

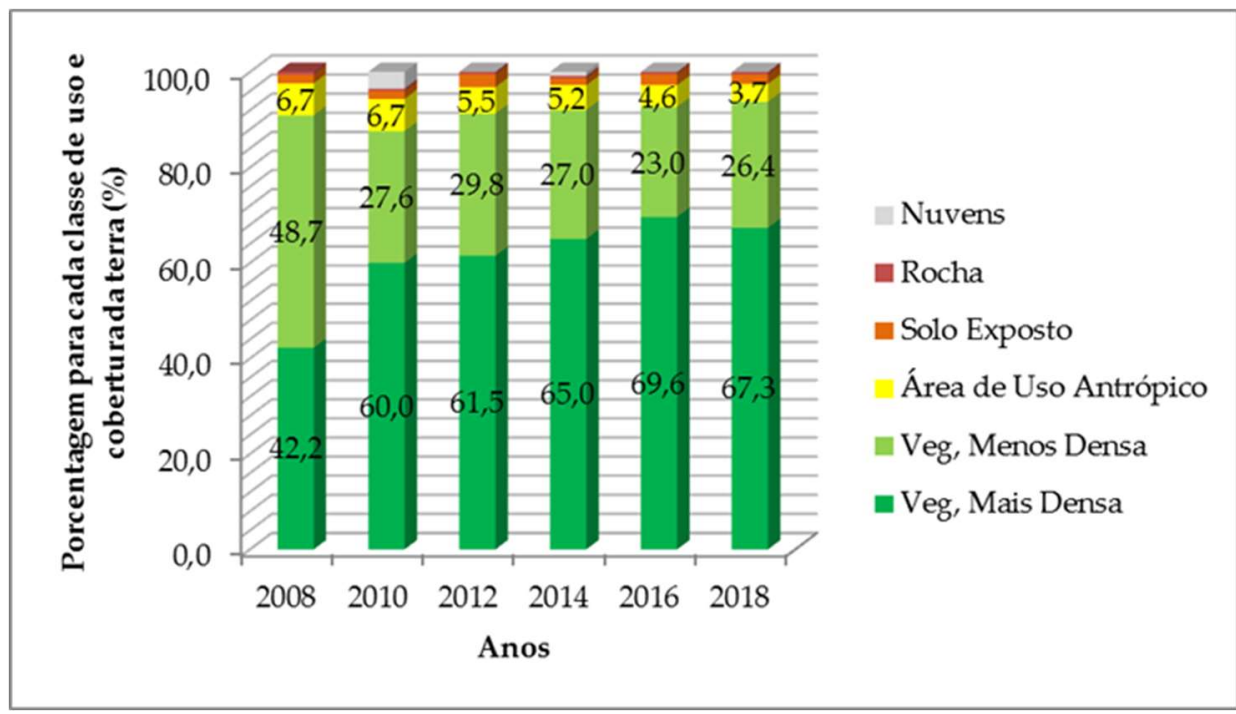

Figura 5: Porcentagem das classes de uso e cobertura da terra do Parque Estadual Mata da Pimenteira ao longo dos períodos pré-criação (2008 - 2010) e pós-criação (2012 - 2014 - 2016 - 2018) da unidade de conservação.

Tabela 5: Área total e porcentagem das classes identificadas para a paisagem do Parque Estadual Mata da Pimenteira no período Pré e Pós-criação da UC.

\begin{tabular}{|c|c|c|c|c|c|c|}
\hline \multirow{2}{*}{ Zona de Amortecimento } & \multicolumn{2}{|c|}{ Pré-criação } & \multicolumn{4}{|c|}{ Pós-criação } \\
\hline & 2008 ha & 2010 ha & 2012 ha & 2014 ha & 2016 ha & 2018 ha \\
\hline Veg. Mais Densa & 374,6 & 532,3 & 545,4 & 576,8 & 617,7 & 597,5 \\
\hline Veg. Menos Densa & 431,9 & 244,9 & 264,4 & 239,8 & 204,5 & 234,3 \\
\hline Área de Uso Antrópico & 59,69 & 59,7 & 49,05 & 45,91 & 40,38 & 33,07 \\
\hline Solo Exposto & 16,03 & 14,62 & 23,68 & 12,82 & 20,08 & 16,96 \\
\hline Nuvens & 4,98 & 4,64 & 4,68 & 4,68 & 4,57 & 5,39 \\
\hline
\end{tabular}

Por fim, a Tabela 6 apresenta as taxas de mudanças anuais das classes de uso e cobertura da terra para a área do Parque Estadual Mata da Pimenteira. Logo, pode ser perceptível que a classe 'vegetação mais densa' mostrou ao longo dos anos mudanças positivas de 2008 a 2016, sendo que apenas entre 2016 e 2018 a taxa de mudança fora negativa revelando perda de massas de vegetação no referido período. Já para a classe 'vegetação menos densa' nota-se perdas de áreas entre 2012 e 2014, ou seja, uma taxa de -0.05\% e no período seguinte a taxa de perda foi superior ao período anterior, mudando negativamente em $-0.08 \%$. A classe referente a 'área de uso antrópico' ao longo dos anos pré e pós-criação da unidade de conservação apresentou taxas de mudanças anuais negativas, revelando ao longo da década uma taxa de $-0.06 \%$. E uma taxa de mudança positiva de $0.01 \%$ para a classe 'solo exposto' durante os 10 anos.

Tabela 6: Taxa de mudanças anuais das classes de uso e cobertura da terra do Parque Estadual da Mata da Pimenteira no período Pré e Pós-criação da UC.

\begin{tabular}{|c|c|c|c|c|c|c|}
\hline \multirow[t]{2}{*}{ Zona de Amortecimento } & \multicolumn{2}{|l|}{ Pré-criação } & \multicolumn{4}{|l|}{ Pós-criação } \\
\hline & $2008-2010$ & $2010-2012$ & $2012-2014$ & $2014-2016$ & $2016-2018$ & $2008-2018$ \\
\hline Veg. Mais Densa & 0,18 & 0,01 & 0,03 & 0,03 & $-0,02$ & 0,05 \\
\hline Veg. Menos Densa & $-0,28$ & 0,04 & $-0,05$ & $-0,08$ & 0,07 & $-0,06$ \\
\hline Área de Uso Antrópico & 0,00 & $-0,10$ & $-0,03$ & $-0,06$ & $-0,10$ & $-0,06$ \\
\hline Solo Exposto & $-0,05$ & 0,24 & $-0,31$ & 0,22 & $-0,08$ & 0,01 \\
\hline
\end{tabular}

\section{Precisão de classificação}

Os resultados obtidos para a obtenção da precisão de classificação das imagens classificadas estão 
apresentados na Tabela 7. Para este estudo, foram selecionados 760 pontos representativos para cada classe identificada a fim de se obter a precisão de classificação (LANDIS et al., 1977) de uso e cobertura da terra e sua concordância com a realidade, levando em conta um erro total esperado de $0.5 \%$. Sendo assim, foram obtidas precisões totais acima dos $90 \%$ para todos os anos analisados, com índice Kappa acima dos 0.9 , caracterizado como uma classificação 'quase perfeita' de concordância com a realidade (LANDIS et al., 1977).

Tabela 7: Precisão de classificação para a paisagem conjunta do entorno e PEMP para cada ano estudado. Legenda: $a=$ precisão do produtor; $b=$ precisão do usuário.

\begin{tabular}{|c|c|c|c|c|c|c|c|c|c|c|c|c|}
\hline \multirow[t]{2}{*}{ Classes de Uso e Cobertura } & \multicolumn{2}{|c|}{2008} & \multicolumn{2}{|c|}{2010} & \multicolumn{2}{|c|}{2012} & \multicolumn{2}{|l|}{2014} & \multicolumn{2}{|c|}{2016} & \multicolumn{2}{|c|}{2018} \\
\hline & $a \%$ & $b \%$ & $a \%$ & $b \%$ & $a \%$ & $b \%$ & $a \%$ & $b \%$ & $a \%$ & $b \%$ & $a \%$ & $b \%$ \\
\hline Água & 92.3 & 97.3 & 98.0 & 97.0 & 94.6 & 99.2 & 96.9 & 97.6 & 97.5 & 99.2 & 96.8 & 97.3 \\
\hline Veg. Mais Densa & 94.6 & 88.1 & 91.3 & 96.5 & 92.2 & 96.8 & 89.7 & 96.7 & 97.9 & 99.3 & 92.9 & 88.1 \\
\hline Veg. Menos Densa & 91.1 & 96.5 & 92.1 & 87.7 & 97.7 & 90.3 & 96.6 & 89.2 & 92.9 & 94.4 & 96.9 & 96.5 \\
\hline Área de Uso Antrópico & 95.2 & 92.3 & 92.6 & 87.7 & 94.4 & 96.0 & 94.5 & 94.5 & 97.5 & 94.2 & 98.0 & 92.3 \\
\hline Solo Exposto & 92.5 & 937.2 & 94.8 & 96.8 & 98.2 & 93.3 & 98.1 & 97.5 & 98.6 & 99.3 & 98.3 & 93.2 \\
\hline Precisão Total (\%) & \multicolumn{2}{|c|}{$93.2 \%$} & \multicolumn{2}{|c|}{$93.7 \%$} & \multicolumn{2}{|l|}{$95 \%$} & \multicolumn{2}{|l|}{$95 \%$} & \multicolumn{2}{|l|}{$97 \%$} & \multicolumn{2}{|c|}{$96.7 \%$} \\
\hline Coeficiente Kappa & \multicolumn{2}{|c|}{0,9127} & \multicolumn{2}{|c|}{0.9197} & \multicolumn{2}{|c|}{0.9369} & \multicolumn{2}{|l|}{0.937} & \multicolumn{2}{|c|}{0.9621} & \multicolumn{2}{|c|}{0.9587} \\
\hline
\end{tabular}

Dinâmica da mudança do uso e cobertura da terra da paisagem do entorno e do PEMP

A partir das análises da Tabela 8 pode ser verificável que as classes apresentaram dinamicidade com ganho e perda de áreas ao longo dos intervalos dos anos. Ao que se nota, como já sinalizado anteriormente, a classe 'Açude' apresentou perdas em porcentagem total de área de $5.86 \%$ durantes os 30 anos, o equivalente a 695.2 hectares, considerando os anos entre 1988 e 2018. Por conseguinte, as 'Área de Transição' ao longo do período pós-criação do Parque Estadual Mata da Pimenteira teve uma redução de 1347.4 hectares, correspondente a $11.36 \%$ da área total da paisagem (zona de amortecimento e parque), sendo que em concordância com a Tabela 6 esta classe mudou para 'Vegetação Arbustiva' em 58.10\% de 2008 a 2018 e permaneceu como 'Área de Transição' em 26.41\%.

Logo, as classes 'Vegetação Arbustiva' e 'Vegetação Arbórea-Arbustiva' apresentaram juntas um crescimento superior a 15\%, correspondente a 1903.3 hectares de área durante o intervalo de 2008 a 2018 (período pós-criação), já para as datas referentes aos período pré-criação as seguintes classes juntas perderam 768.3 hectares durante 1998 e 2008, equivalente a 6.48\%. As demais classes que tipificam o uso e cobertura da terra quanto ao 'Solo Exposto' também apresentou mudança positiva de 917 hectares (7.73\%) entre 2008 a 2018 e 'Uso Antrópico' teve redução de áreas ao longo de todos os anos estudados.

Tabela 8: Dinâmica da mudança da área (ha) intraclasses de tipos de usos e coberturas da terra ao longo dos 30 anos analisados.

\begin{tabular}{|l|l|l|l|l|}
\hline \multirow{2}{*}{ Tipos de Uso e Cobertura da Terra } & \multicolumn{4}{l|}{ Mudanças por intervalo de tempo } \\
\cline { 2 - 5 } & $\mathbf{1 9 8 8 - 1 9 9 8}$ & $\mathbf{1 9 9 8 - 2 0 0 8}$ & $\mathbf{2 0 0 8 - 2 0 1 8}$ & $\mathbf{1 9 8 8 - 2 0 1 8}$ \\
\cline { 2 - 5 } & Área (ha) & Área (ha) & Área (ha) & Área (ha) \\
\hline Açude & -734.7 & 436.5 & -397 & -695.2 \\
\hline Área de Transição & -160.4 & 762.6 & -1347.4 & -745.2 \\
\hline Vegetação Arbustiva & 594.1 & -577.8 & 1294 & 1310.3 \\
\hline Vegetação Arbórea-Arbustiva & 77.3 & -190.5 & 609.3 & 496 \\
\hline Solo Exposto & 230.9 & -349.8 & 917 & 798.1 \\
\hline Uso Antrópico & -12.7 & -67.3 & -1048.6 & -1128.7 \\
\hline
\end{tabular}

A Tabela 9 apresenta o comportamento de transição de uma determinada classe de uso e cobertura 
da terra para outra, a fim de diagnosticar a dinâmica da mudança da paisagem no decorrer dos anos. Desta forma, percebe-se que para classe 'Açude' ao longo do tempo transicinou para as classes 'Solo Exposto e Uso Antrópico' em 17.96\% e 27.79\%, respectivamente nos intervalos de 1988 a 1998. Já para o período situado entre 2008 a 2018 a mesma classe mudou para 'Vegetação Arbustiva', em 17,91\%, 'Vegetação ArbóreaArbustiva', em 13,96\%, vale ressaltar que neste caso em específico, esta categoria corresponde a vegetação com menor estresse hídrico. Por fim, transicinou em 25.64\% e 16.39\%, 'Solo Exposto' e 'Uso Antrópico', respectivamente.

Quanto às classes indicadoras da presença de vegetação na paisagem apresentaram comportamento mais significativo de transição intraclasse, pois durante os intervalos pode ser verificável que a 'Vegetação Arbustiva' permanece dentro da mesma categoria em 70.71\% entre 1988 a 1998 e $65.92 \%$ entre os anos de 2008 a 2018. Contudo, entre os anos de 1998 a 2008 pode ser verificável que esta categoria cedeu espaço em 31.50\% para as 'Área de Transição', refletindo a supressão de vegetação em um dado momento posterior e consequentemente sua recomposição vegetal com espécies pioneiras. Além disso, $12.96 \%$ desta transicinou para as classes características de atividade humana, 'Solo Exposto' e 'Uso Antrópico'. Ao analisar a interação desta classe junto às demais é perceptível que o período pós-criação da unidade de conservação proporcionou uma maior estabilidade da vegetação da paisagem, levando a crer que sob os aspectos conservacionistas, o Parque Estadual Mata da Pimenteira obteve sucesso quanto a recuperação das áreas outrora degradadas e permitiu o crescimento da vegetação no seu entorno.

No tocante ao cenário atual total, levando em conta o período de 1988 a 2018, as classes 'Solo Exposto' e 'Uso Antrópico' transacionaram juntas em 46.51\% para 'Vegetação Arbustiva', corroborando a percepção da recuperação das áreas, em contrapartida, a primeira classe (Solo Exposto" teve um crescimento considerável no mesmo período.

Tabela 9: Matriz de transição com percentual de mudança interclasses dos principais tipos de uso e cobertura da terra ao longo dos anos analisados, no Parque Estadual Mata da Pimenteira, Serra Talhada/PE.

\begin{tabular}{|l|l|l|l|l|l|l|}
\hline $\mathbf{1 9 8 8 - 1 9 9 8 ~ ( \% ) ~}$ & $\mathbf{1}$ & $\mathbf{2}$ & $\mathbf{3}$ & $\mathbf{4}$ & $\mathbf{5}$ & $\mathbf{6}$ \\
\hline $\mathbf{1}$ & 25.62 & 17.09 & 7.98 & 3.41 & 17.96 & 27.79 \\
\hline $\mathbf{2}$ & 0.00 & 31.58 & 39.67 & 0.40 & 7.08 & 21.17 \\
\hline $\mathbf{3}$ & 0.00 & 10.73 & 70.71 & 10.08 & 1.55 & 6.52 \\
\hline $\mathbf{4}$ & 0.00 & 4.48 & 18.31 & 59.95 & 2.87 & 3.86 \\
\hline $\mathbf{5}$ & 0.00 & 15.73 & 1.52 & 0.00 & 51.17 & 31.45 \\
\hline $\mathbf{6}$ & 0.00 & 38.55 & 9.75 & 0.09 & 17.48 & 34.07 \\
\hline $\mathbf{1 9 9 8 - 2 0 0 8 ( \% )}$ & $\mathbf{1}$ & $\mathbf{2}$ & $\mathbf{3}$ & $\mathbf{4}$ & $\mathbf{5}$ & $\mathbf{6}$ \\
\hline $\mathbf{1}$ & 99.79 & 0.00 & 0.00 & 0.14 & 0.00 & 0.07 \\
\hline $\mathbf{2}$ & 6.47 & 58.66 & 13.78 & 0.57 & 3.44 & 16.97 \\
\hline $\mathbf{3}$ & 2.71 & 31.50 & 50.55 & 2.22 & 3.67 & 9.29 \\
\hline $\mathbf{4}$ & 5.00 & 1.46 & 43.69 & 39.14 & 0.84 & 1.80 \\
\hline $\mathbf{5}$ & 6.55 & 13.29 & 1.35 & 1.10 & 38.89 & 38.56 \\
\hline $\mathbf{6}$ & 9.84 & 36.67 & 4.04 & 0.90 & 9.62 & 38.70 \\
\hline $\mathbf{2 0 0 8 - 2 0 1 8 ( \% )}$ & $\mathbf{1}$ & $\mathbf{2}$ & $\mathbf{3}$ & $\mathbf{4}$ & $\mathbf{5}$ & $\mathbf{6}$ \\
\hline $\mathbf{1}$ & 41.30 & 0.22 & 17.91 & 13.86 & 12.41 & 14.13 \\
\hline $\mathbf{2}$ & 0.04 & 26.41 & 58.10 & 1.38 & 9.22 & 4.64 \\
\hline $\mathbf{3}$ & 0.08 & 3.00 & 65.92 & 28.16 & 1.26 & 1.35 \\
\hline $\mathbf{4}$ & 0.89 & 0.36 & 10.21 & 79.83 & 1.81 & 1.71 \\
\hline $\mathbf{5}$ & 0.02 & 5.22 & 4.05 & 0.17 & 81.55 & 8.94 \\
\hline $\mathbf{6}$ & 0.05 & 26.02 & 14.77 & 0.56 & 44.61 & 13.67 \\
\hline $\mathbf{1 9 9 8 - 2 0 1 8 ( \% )}$ & $\mathbf{1}$ & $\mathbf{2}$ & $\mathbf{3}$ & $\mathbf{4}$ & $\mathbf{5}$ & $\mathbf{6}$ \\
\hline $\mathbf{1}$ & 29.45 & 1.18 & 16.30 & 10.90 & 25.64 & 16.39 \\
\hline
\end{tabular}




\begin{tabular}{|l|l|l|l|l|l|l|}
\hline $\mathbf{2}$ & 0.03 & 20.28 & 55.76 & 4.22 & 13.37 \\
\hline $\mathbf{3}$ & 0.02 & 5.87 & 62.55 & 18.97 & 8.73 & 3.24 \\
\hline $\mathbf{4}$ & 0.02 & 0.64 & 12.15 & 77.85 & 3.95 \\
\hline $\mathbf{5}$ & 0.05 & 19.66 & 12.46 & 0.72 & 3.07 \\
\hline
\end{tabular}

\section{DISCUSSÃO}

O domínio Caatinga faz parte da maior floresta tropical sazonalmente seca localizada na América do Sul, junto com as porções florestais situadas ao sudoeste da Bolívia, Paraguai e norte da Argentina (SILVA et al., 2018). Ela ocupa $10.7 \%$ do território nacional, o que corresponde a $912.529 \mathrm{~km}^{2}$, equivalente a soma dos territórios da Itália, Alemanha e Reino Unido juntos (ESPIRITO-SANTO et al., 2009). Além disso, é considerada um dos ecossistemas mais ameaçados no Brasil, atrás apenas da Mata Atlântica e Cerrado (GANEM, 2019).

De acordo com Teixeira (2016) existem apenas 129 unidades de conservação situadas dentro dos limites geográficos do domínio Caatinga, sendo que apenas 1.2\% destas estão sob a forma de UC's do grupo de Proteção Integral, o qual por sua vez, mantém regras mais rígidas quanto aos usos dos recursos naturais. Por conseguinte, 6.3\% estão enquadrados no grupo de Uso Sustentável e possuem pequenas áreas.

O Parque Estadual Mata da Pimenteira possui uma área de 853.7 há, apesar disso é cercada em sua totalidade por atividades de uso e cobertura diversificadas, conforme apresentados anteriormente. Portanto, a unidade de conservação se apresenta como uma ilha isolada de conectividade com demais formações vegetais protegidas, sem corredores ecológicos, entre outros. Conforme afirma Smith et al. (2010) áreas protegidas isoladas e pequenas são menos ecologicamente viáveis e mais caras de se gerir. Estão mais propensas aos efeitos de borda (LAURANCE et al., 2002). Contudo podem ser mais viáveis quando as espécies protegidas possuem baixo risco de extinção (SHAFER, 1995), além disso, quando em conjunto com demais áreas protegidas de pequenos tamanhos podem apresentar mais viabilidade de conservação se ao longo prazo o número de áreas protegidas acompanhar o crescimento no número de espécies (ROBERT, 2009).

Com base nisso, sabe-se que as populações "sertanejas" típicas da região são dependentes quase que em sua maioria dos recursos naturais disponíveis, principalmente devido às condições socioeconômicas desfavoráveis da população. Como consequência estes são forçados ao uso das plantas e recursos animais disponíveis, revelando assim não apenas a importância para a manutenção das comunidades tradicionais, mas também sua relevância econômica (ALBUQUERQUE et al., 2018).

A Mata da Pimenteira é o primeiro resultado, do esforço do estado de Pernambuco, em criar uma UC e preservar fragmentos de Caatinga em seu território, devido a isso recebe a alcunha de primeira unidade de conservação estadual. Logo, sabe que o número de estudos voltados para o entendimento das características da dinâmica dos usos e coberturas da terra neste domínio são poucos (SCHULZE et al., 2018). E ao restringir os estudos da ocorrência desse fenômeno dentro das áreas protegidas e seus entornos são insuficientes.

Examinando o comportamento das classes de usos e cobertura da terra da paisagem estudada, percebeu-se que a criação do Parque Estadual Mata da Pimenteira promoveu uma reorganização da dinâmica da paisagem, principalmente no estabelecimento de áreas com maior incidência de vegetação, simbolizando 
a recuperação de áreas. O mesmo resultado pode ser constatado por Bilar et al. (2018) onde através dos índices biofísicos de vegetação (NDVI, NDWI, SAVI e LAI) observou que a vegetação do parque está relativamente bem preservada, indicando melhores condições nos períodos pós-criação da UC.

Apesar disso, conforme afirma Defries et al. (2007) diversas áreas protegidas ao redor do mundo estarão sob constante pressão, principalmente em decorrência dos tipos de usos empregados a terra. Logo, foi observado que a respeito disso, as classes indicadoras de usos sobre a paisagem, "Solo Exposto" e "Uso Antrópico" apresentaram um recuo das fronteiras da área protegida, principalmente a oeste da Pimenteira, onde estão localizados os assentamentos Lajinha, Carnaúba do Ajudante, Cachoeira II e demais propriedades privadas. Entretanto, a classe "Solo Exposto" concentrou-se dentro dos limites dos assentamentos e fazendas, permanecendo a mesma categoria em $60.47 \%$ ao longo dos 30 anos estudados (Tabela 6), ou seja, apesar do aumento dos índices de vegetação para além das fronteiras da UC, a dinamicidade e intensificação dos usos antrópicos aumentaram. Sendo assim, conforme corrobora (SILVA et al., 2016) a exposição direta do solo a radiação solar eleva a temperatura da superfície e consequentemente a do ar, ocasionando a diminuição do sequestro de carbono das áreas degradadas.

Além disso, o crescimento populacional no entorno da Mata da Pimenteira tende a provocar alguns conflitos ao longo dos anos, pois aumenta as pressões sobre o espaço, a busca por mais recursos para suprir as necessidades diárias destas comunidades. Bailey et al. (2016) em seus estudos, observaram que as mudanças do uso e cobertura nas áreas circundantes de áreas protegidas, principalmente práticas agrícolas podem provocar significativos impactos, como, redução da matéria orgânica do solo e indução a degradação do solo. Ainda em concordância com Bailey et al. (2016) tais eventos em linhas gerais, principalmente decorrentes das mudanças dos usos e cobertura tendem a acirrar os conflitos entre humanos e a vida selvagem, extração ilegal dos recursos naturais, declínio da produtividade dos habitats, entre outros.

As mudanças climáticas são fatores de extrema importância no tocante a intensificação das mudanças de uso e cobertura da terra, principalmente ao se tratar dos impactos decorrentes dessa dinâmica. Conforme Cunha et al. (2015) às mudanças do uso e cobertura da terra em regiões semiáridas ajudam a promover significativas -alterações na temperatura da superfície próxima. Os autores afirmam que levando em conta o tipo de fitofisionomia da Caatinga as transições de florestas para pastagens podem provocar um resfriamento anual que varia de -1.8 a $-0.3^{\circ} \mathrm{C}$ e em outras regiões a transição de Caatinga para Caatinga degradada aumentou de 0.3 a $0.9^{\circ} \mathrm{C}$.

\section{CONCLUSÕES}

Atualmente o Brasil tem enfrentado forças políticas contrárias aos objetivos conservacionistas, e até mesmo, de inclusão e desenvolvimento social. Tal situação tende a refletir sobre as políticas nacionais de promoção do desenvolvimento sustentável e principalmente da conservação e preservação dos domínios naturais ameaçados, dentre estes, a Caatinga. Para tanto, o debate social quanto a continuidade e incentivos na gestão dos recursos naturais crescem em todo país.

A partir desta pesquisa pode-se perceber que as mudanças dos usos e coberturas da terra são 
caracterizadas como ameaças a biodiversidade tanto em escala local quanto global, o que atinge não apenas países em desenvolvimento, bem como também os países ricos. Afinal das contas este é um fenômeno que está intrinsecamente interligado a presença humana no espaço.

Portanto, constatou-se que apesar da intensificação do uso sobre as áreas do entorno da Mata da Pimenteira, pode ser constatado que as áreas vegetadas expandiram em direção às áreas habitadas, o que pode refletir em potencial conflito futuro. Contudo, as áreas exclusivamente protegidas dentro dos limites do parque também apresentaram tendências de crescimento ao longo dos 30 anos analisados. Mas os crescimentos dos usos no entorno podem suscitar a uma dinamicidade de impactos principalmente quando associados às mudanças climáticas, com baixos índices de precipitação e estiagem mais severas. Ao que decorrer disso, notou-se também que os principais recursos hidrológicos do entorno são os principais afetados quando as secas se instalam sobre a paisagem, provocando assim, perdas de recursos econômicos e de abastecimento para a população do entorno.

Logo, recomenda-se que sejam realizados mais estudos voltadas às mudanças do uso e cobertura da terra, da dinâmica da paisagem, e do acompanhamento do crescimento da vegetação de forma contínua, a fim de monitoramento, assim como também, estudos voltados às interações socioambientais entre as comunidades do entorno e a área protegida, a fim de diagnosticar como essa dinâmica favorece a estimulação de uma gestão mais participativa e inclusiva.

Além disso, apesar de primária, esta informação permite perceber que o estabelecimento de áreas protegidas, ao menos neste caso em específico, auxiliou na melhoria da recuperação de áreas desvegetadas, e em última instância, na recomposição vegetal arbustiva de áreas outrora degradadas.

AGRADECIMENTOS: Agradeço a Coordenação de Aperfeiçoamento de Pessoal de Nível Superior - CAPES pela bolsa concedida, a Universidade Federal Rural de Pernambuco, Unidade Acadêmica de Serra Talha, ao Programa de Pós-graduação em Biodiversidade e Conservação - PGBC e ao Laboratório Interdisciplinar de Anfíbios e Répteis pelo apoio e estrutura concedida.

\section{REFERÊNCIAS}

AHMED, O. S.; SHEMROCK, A.; CHABOT, D.; DILLON, C.; WILLIAMS, G.; WASSON, R.; FRANKLIN, S. E.. Hierarchical land cover and vegetation classification using multispectral data acquired from an unmanned aerial vehicle. International Journal of Remote Sensing, v.38, p.2037-2052 2017. DOI: http://doi.org/10.1080/01431161.2017.1294781

ALBUQUERQUE, U. P.; ARAÚJO, E. L.; CASTRO, C. C.; ALVES, R. R. N.. People and Natural Resources in the Caatinga. In: SILVA, J. M. C.; LEAL, I. R.; TABARELLI, M.. Caatinga: The largest Tropical Dry Forest Region in South America. Springer, 2018. p.303-333. DOI: http://doi.org/10.1007/9783-319-68339-3

BADJANA, H. M.; HELMSCHROT, J.; SELSAM, P.; WALA, K.; FLÜGEL, W. A.; AFOUDA, A.; AKPAGANA, K.. Land cover changes assessment using object-based image analysis in the Binah River watershed (Togo and Benin). Earth and Space
Science, v.2, p.403-416, 2015. DOI: http://doi.org/10.1002/2014EA000083

BAILEY, K. M.; MCCLEERY, R. A.; BINFORD, M. W.; ZWEIG, C.. Land-cover change within and around protected areas in a biodiversity hotspot. Journal of Land Use Science, v.11, p.154-176, 2016. DOI:

http://dx.doi.org/10.1080/1747423X.2015.1086905

BEUCHLE, R.; GRECCHI, R. C.; SHIMABUKURO, Y. E.; SELIGER, R.; EVA, H. D.; SANO, E.; ACHARD, F.. Land cover changes in the Brazilian Cerrado and Caatinga biomes from 1990 to 2010 based on a systematic remote sensing sampling approach. Applied Geography, v.58, p.116-127, 2015. DOI: http://doi.org/10.1016/j.apgeog.2015.01.017

BILAR, A. B. C.; PIMENTEL, R. M. M.; CERQUEIRA, M. A.. monitoramento da cobertura vegetal através de índices 
biofísicos e gestão de áreas protegidas. Geosul, v.33, p.236259, 2018. DOI: http://dx.doi.org/10.5007/2177$\underline{5230.2018 v 33 n 68 p 236}$

BRASIL. Lei Federal n. 9.985, de 18 de julho de 2000. Regulamenta o art. 225, §10, incisos I, II, III e VII da Constituição Federal, institui o Sistema Nacional de Unidades de Conservação da Natureza e dá outras providências. DOU, 2000.

BRASIL. Monitoramento da Caatinga. Brasilia: IBAMA, 2019

Cohen, J.. A Coefficient of Agreement for Nominal Scales. Educational and psychological measurement, v.20, p.37-46, 1960. DOI: http://doi.org/10.1177/001316446002000104

CUNHA, A. P. M. A.; ALVALÁ, R. C. S.; KUBOTA, P. Y.; VIEIRA, R. M. S. P.. Impacts of land use and land cover changes on the climate over Northeast Brazil. Atmospheric Science Letters, v.16, p.219-227, 2015. DOI:

http://doi.org/10.1002/asl2.543

DEFRIES, R.; HANSEN, A.; TURNER, B. L.; REID, R.; LIU, J.. Land use change around protected areas: management to balance human needs and ecological function. Ecological

Applications, v.17, p.1031-1038, 2007. DOI:

http://doi.org/10.1890/05-1111

ESPIRITO-SANTO, M. M.; SEVILHA, A. C.; ANAYA, F. C.; BARBOSA, R.; FERNANDES, G. W.; SANCHEZ-AZOFEIFA, G. A.; SCARIOT, A.; NORONHA, S. E.; SAMPAIO, C. A.. Sustainability of tropical dry forests: Two case studies in southeastern and central Brazil. Forest Ecology and Management, v.258, p.922-930, 2009. DOI: http://doi.org/10.1016/j.foreco.2009.01.022

FRANÇA-ROCHA, W.; SILVA, A. D. B.; NOLASCO, M. C.; LOBÃO, J.; BRITTO, D.; CHAVES, J. M.; ROCHA, C. D.. Levantamento da cobertura vegetal e do uso do solo do Bioma Caatinga. In: SIMPÓSIO BRASILEIRO DE SENSORIAMENTO REMOTO, 13. Anais. Florianópolis: INPE, 2007. p.2629-2636.

\section{FIGUEIRÊDO, C. T.; SOUZA, A. V. M.. Conflitos}

socioambientais em áreas protegidas: $\mathrm{O}$ Parque Nacional $\mathrm{Da}$ Serra De Itabaiana, em Sergipe. Cadernos De Ciências Sociais Aplicadas, 2013.

FERRAZ, E. M. N.; RODAL, M. J. N.; SAMPAIO, E. V.; PEREIRA, R. D. C. A.. Composição florística em trechos de vegetação de caatinga e brejo de altitude na região do Vale do Pajeú, Pernambuco. Brazilian Journal of Botany, v.21, p.7-15, 1998.

GANEM, R. S.. Caatinga: Estartaégias de Conservação. Brasilia: Camara Legislativa, 2019.

HUMMEL, C.; POURSANIDIS, D.; ORENSTEIN, D.; ELLIOTT, M.; ADAMESCU, M. C.; CAZACU, C.; ZIV, G.; CHRYSOULAKIS, N.; VAN DER MEER, J.; HUMMEL, H.. Protected Area management: Fusion and confusion with the ecosystem services approach. Sci. Total Environ, v.651, p.2432-2443, 2018. DOI: http://doi.org/10.1016/J.SCITOTENV.2018.10.033

HÜTT, C.; KOPPE, W.; MIAO, Y.; BARETH, G.. Best accuracy land use/land cover (LULC) classification to derive crop types using multitemporal, multisensor, and multi-polarization SAR satellite images. Remote Sensing, v.8, p.684, 2016. DOI: http://doi.org/10.3390/rs8080684

JIA, B.; ZHANG, Z.; CIA, L.; REN, Y.; PAN, B.; ZHANG, Z.. Oasis land-use dynamics and its influence on the oasis environment in Xinjiang, China. Journal of Arid Environments, v.56, p.11-26, 2004. DOI: http://doi.org/10.1016/S0140-1963(03)00002-8

JUSYS, T.. Quantifying avoided deforestation in Pará:

Protected areas, buffer zones and edge effects. Journal for Nature Conservation, v.33, p.10-17, 2016. DOI: http://dx.doi.org/10.1016/j.jnc.2016.05.001

LANDIS, J. R.; KOCH, G. G.. The Measurement of Observer Agreement for Categorical Data. International Biometric Society, v.33, p.159-174, 1977. DOI: http://doi.org/10.2307/2529310

LAURANCE, W. F.; LOVEJOY, T. E.; VASCONCELOS, H. L.; BRUNA, E. M.; DIDHAM, R. K.; STOUFFER, P. C.; GASCON, C.; BIERREGAARD, R. O.; LAURANCE, S. G.; SAMPAIO, E..

Ecosystem decay of Amazonian forest fragments: a 22-year investigation. Conservation Biology, v.16, p.605-618, 2002. DOI: http://doi.org/10.1046/j.1523-1739.2002.01025.x

LI, Y.; ZHANG, H.; XU, X.; JIANG, Y.; SHEN, Q.. Deep learning for remote sensing image classification: A survey. WIREs Data Mining and Knowledge Discovery, p.1-17, 2018. DOI: http://doi.org/10.1002/widm.1264

LIMA, E. A. C. F.; RANIERI, V. E. L.. Land use planning around protected areas: Case studies in four state parks in the Atlantic forest region of southeastern Brazil. Land Use Policy, v.71, p.453-458, 2018. DOI: http://doi.org/10.1016/j.landusepol.2017.12.020

RAWAT, J. S.; KUMAR, M.. Monitoring land use/cover change using remote sensing and GIS techniques: A case study of Hawalbagh block, district Almora, Uttarakhand, India. The Egyptian Journal of Remote Sensing and Space Science, v.18, p.77-84, 2015. DOI: http://dx.doi.org/10.1016/j.ejrs.2015.02.002

ROBERT, A.. The effects of spatially correlated perturbations and habitat configuration on metapopulation persistence. Oikos, v.118, p.1590-1600, 2009. DOI: http://doi.org/10.1111/j.1600-0706.2009.17818.x

SANTOS, E. M.; ALMEIDA, G. V. L.; OLIVEIRA, L. L. D. S. S.; MENESES, E. R. A.; GUEDES, M. V.; BRITO, J. V. A.; SANTOS, J. C.. O Parque Estadual Mata da Pimenteira - primeira unidade de conservação estadual da caatinga de Pernambuco. In: SANTOS, E. M.; MELO JUNIOR, M.; SILVA-CAVALCANTI, J. S.; ALMEIDA, G. V. L.. Parque Estadual Mata da Pimenteira: Riqueza Natural e Conservação da Caatinga. Recife: EDUFRPE, 2013. p.15-26.

SILVA, J. M. C.; BARBOSA, L. C. F.; LEAL, I. R.; TABARELLI, M. The Caatinga: understanding the challenges. In: SILVA, J. M. C.; LEAL, I. R.; TABARELLI, M.. Caatinga: The largest Tropical Dry Forest Region in South America. Springer, 2018. p.3-19. DOI: http://doi.org/10.1007/978-3-319-68339-3

SILVA, D. G.; ARRUDA, I. R. P.; SILVA, M. L. G.; FERREIRA, P. S.; GOMES, V. P.. Análise espaço-temporal do uso e cobertura da terra no município de Exu, PE. Clio 
Arqueológica, v.31, p.193-2010, 2016. DOI: http://doi.org/10.20891/clio.V31N3p193-210

SHAFER, C. L.. Values and shortcomings of small reserves. BioScience, v.45, p.80-88, 1995. DOI:

http://doi.org/10.2307/1312609

SCHULZE, K.; KNIGHTS, K.; COAD, L.; GELDMANN, J.; LEVERINGTON, F.; EASSOM, A.; MARR, M.; BUTCHART, S. H. M.; HOCKINGS, M.; BURGESS, N. D.. An assessment of threats to terrestrial protected areas. Conservation Letters, v.11, p.e12435, 2018. DOI:

http://doi.org/10.1111/conl.12435

SMITH, R. J.; MININ, E. D.; LINKE, S.; SEGAN, D. B.; POSSINGHAM, H. P.. An approach for ensuring minimum protected area size in systematic conservation planning. Biological Conservation, v.143, p.2525-2531, 2010. DOI: http://doi.org/10.1016/j.biocon.2010.06.019
TEIXEIRA, M. G.. Unidades de conservação da Caatinga: Distribuição e contribuições para conservação. Dissertação (Mestrado) - Universidade Federal do Rio Grande do Norte, Natal, 2016.

USMAN, B.. Satellite Imagery Land Cover Classification using K-Means Clustering Algorithm Computer Vision for Environmental Information Extraction. Elixir Comp. Sci. \& Engg, v.63, p.18671-18675, 2013.

WATSON, J. E.; DUDLEY, N.; SEGAN, D. B.; HOCKINGS, M.. The performance and potential of protected areas. Nature, v.515, p.67, 2014. DOI: http://doi.org.10.1038/nature13947

YE, B.; BAI, Z.. Simulating land use/cover changes of Nenjiang County based on CA-Markov model. In: INTERNATIONAL CONFERENCE ON COMPUTER AND COMPUTING TECHNOLOGIES IN AGRICULTURE. Anais. Springer, 2007. p.321-329. DOI: http://doi.org/10.1007/978-0-387-77251 635

A CBPC - Companhia Brasileira de Produção Científica (CNPJ: 11.221.422/0001-03) detém os direitos materiais desta publicação. Os direitos referem-se à publicação do trabalho em qualquer parte do mundo, incluindo os direitos às renovações, expansões e disseminações da contribuição, bem como outros direitos subsidiários. Todos os trabalhos publicados eletronicamente poderão posteriormente ser publicados em coletâneas impressas sob coordenação da Sustenere Publishing, da Companhia Brasileira de Produção Científica e seus parceiros autorizados. Os (as) autores (as) preservam os direitos autorais, mas não têm permissão para a publicação da contribuição em outro meio, impresso ou digital, em português ou em tradução. 